\title{
TERAPÊUTICA CLÍNICA DOS PROBLEMAS OCULARES
}

\author{
CLINICAL THERAPEUTIC OF OCULAR PROBLEMS
}

Sidney Júlio de Faria e Sousa

Docente do Departamento de Oftalmologia e Otorrinolaringologia da Faculdade de Medicina de Ribeirão Preto da Universidade de São Paulo.

CORRESPONDÊNCIA: Departamento de Oftalmologia e Otorrinolaringologia da Faculdade de Medicina de Ribeirão Preto - Campus Universitário - CEP: 14048-900 - São Paulo - SP - Fax: (016) 633-0186.

FARIA e SOUSA SJ de. Terapêutica clínica dos problemas oculares. Medicina, Ribeirão Preto, 30: 90-93, jan./mar. 1997.

RESUMO: Existe um arsenal farmacológico muito vasto para o diagnóstico e tratamento dos problemas oculares. As vias de administração incluem a tópica, subconjuntival, retrobulbar e sistêmica. O presente trabalho faz um resumo das principais medicações oculares de uso corrente, separadas em agrupamentos terapêuticos.

UNITERMOS: Terapêutica. Farmacologia. Medicamentos. Olho.

\section{VIAS DE ADMINISTRAÇÃO DAS MEDICAÇÕES OFTALMOLÓGICAS}

São quatro as vias usadas para a introdução de medicações nos tecidos oculares: tópica, subconjuntival, retrobulbar e sistêmica.

A via tópica é a dos colírios oftálmicos. Garante altas concentrações nos tecidos superficiais do olho, câmara anterior, íris e corpo ciliar com instilações freqüentes no saco conjuntival. Permite, ainda, o uso de medicamentos de alta toxicidade sistêmica como a neomicina e o nitrato de prata. A via subconjuntival é usada em substituição à tópica, nos casos em que não haja possibilidade ou interesse de se fazerem freqüentes instilações de colírio. A via retrobulbar é uma alternativa à via sistêmica. É escolhida, quando se desejam altas concentrações de medicações no pólo posterior do olho, inclusive no corpo vítreo. É muito usada nas anestesias locais para cirurgias de catarata, transplantes e outras. A via sistêmica constitui forma eficaz de terapêutica das doenças intra-oculares. A eficiência dessa via é limitada pela toxicidade das medicações e pela barreira hematoaquosa. Essa barreira é particularmente importante para os antibióticos.

\section{PRINCIPAIS AGENTES TERAPÊUTICOS}

\section{Parassimpaticolíticos}

Esses agentes são utilizados, em Oftalmologia, como inibidores do músculo ciliar e como dilatadores da pupila. O relaxamento do músculo ciliar alivia a dor das iridociclites e inibe a acomodação nos exames da refração ocular.

A midríase ocorre por bloqueio do músculo dilatador da íris. É utilizada nos exames do fundo do olho e na prevenção de sinéquias inflamatórias da íris com o cristalino. Os principais produtos do mercado são:

- Atropina colírio 0.5\% e 1.0\%: cicloplégico forte e de ação prolongada (até 10 dias). Usado freqüentemente nas inflamações oculares.

- Ciclopentolato colírio 1.0\%: cicloplégico forte, com duração de 8 a 12 horas. Muito usado nos exames refratométricos e boa alternativa para as inflamações oculares.

- Tropicamida colírio $0.5 \%$ e $1 . \%$ : duração de 3 a 5 horas. Excelente para midríase, razoável para uso nas uveítes anteriores discretas e refratometria. 
A toxicidade dos parassimpaticolíticos decresce da atropina para a tropicamida. A absorção sistêmica se manifesta por sonolência, rubor e febre discreta. Raramente se observa incoordenação motora, desorientação e alucinação. Felizmente, todas essas manifestações tendem a desaparecer espontaneamente, em uma hora.

\section{Parassimpaticomiméticos}

As principais indicações do uso tópico são a constrição pupilar (miose) e a melhora do escoamento do humor aquoso pelo trabeculado. A miose se processa por estímulo do músculo constritor das pupilas. É útil na contraposição da midríase farmacológica ou da midríase do glaucoma agudo. A melhora do escoamento do aquoso deve-se ao estiramento das malhas do trabeculado, propriedade esta utilizada no tratamento do glaucoma crônico.

As principais medicações de uso tópico disponíveis no nosso mercado são:

- Pilocarpina colírio 2\% e 4\%: duração de 6 a 8 horas. Provoca miose, espasmo do músculo ciliar e facilita o escoamento do aquoso ao nível do trabeculado.

- Carbacol solução de $0,75 \%$ : usado para miose intracirúrgica da pupila, em cirurgias de catarata e transplante de córnea.

A toxicidade é baixa. São mais comuns as queixas referentes ao espasmo da acomodação: embaçamento visual e cefaléia frontal. A miose intensa pode atrapalhar a visão noturna.

\section{Simpatomiméticos}

Na forma de colírios, são indicados para provocar midríase e inibição da produção do humor aquoso. A dilatação da pupila ocorre por estímulo do músculo dilatador da pupila. A vantagem sobre a midríase, provocada pelos parassimpaticolíticos, é que ela não inibe o músculo ciliar. Não causa, portanto, embaçamento. As principais medicações disponíveis são:

- fenilefrina colírio a 10\%: usada para dilatação da pupila, isolada ou associada a cicloplégicos. Útil para exames de fundoscopia.

- epinefrina a $1 \%$ e $2 \%$ : usada no tratamento do Glaucoma crônico, pois inibe a produção do aquoso. Produz pequena midríase.

A absorção sistêmica pode causar palpitações e arritmias. Já foram descritas crises hipertensivas graves com fenilefrina a $10 \%$. Nos Estados Unidos, a concentração desse colírio é de $2,5 \%$.

\section{Simpaticolíticos}

Agentes simpatolíticos, betabloqueadores seletivos, são utilizados na inibição da produção do humor aquoso. Servem, portanto, para tratamento dos glaucomas crônicos. As principais medicações disponíveis são:

- Timolol $0.25 \%$ e $0.5 \%$ : Timoptol®

- Betaxolol 0,25\% e 0.5\%: Betoptic $®$

A absorção sistêmica pode causar bradicardia, bloqueio cardíaco, broncoespasmo e falha respiratória. O primeiro tem mais possibilidades de reações adversas respiratórias que o segundo; deve ser evitado, portanto, em pacientes asmáticos.

\section{Anestésicos tópicos}

$\mathrm{Na}$ forma de colírios, são indicados para suprimir a dor de origem corneana ou dos envoltórios externos do olho. Só devem ser usados, pelo médico, para exame ocular ou procedimentos cirúrgicos na superfície do globo. As situações mais freqüentes em que são usados, incluem: (1) exame do olho irritado; (2) retirada de corpos estranhos da córnea; (3) cirurgias de pterígeo e conjuntiva; (4) diagnóstico diferencial entre dor corneana e ciliar. Não devem ser usados em injeções subconjuntivais, em virtude da possibilidade de toxicidade sistêmica. $\mathrm{O}$ anestésico mais usado para a via subconjuntival é a xilocaína $1,0 \%$ ou $2 \%$.

Os principais colírios disponíveis no mercado são:

- proparacaína: Anestalcon ${ }^{\circledR}$

- tetracaína: Colírio Anestésico ${ }^{\circledR}$

Os riscos de uso prolongado são: (1) inibição da regeneração do epitélio corneano, levando a úlceras graves; (2) alergia grave; (3) exposição da córnea por inibição do reflexo de piscagem.

\section{Corantes}

Os corantes, em forma de colírios ou bastões de papel, são indicados para: (1) detecção de descontinuidade do epitélio corneano; (2) detecção de células desvitalizadas para diagnóstico do olho seco; (3) estudo da espessura e continuidade do filme lacrimal.

Os principais corantes usados em Oftalmologia são:

- fluoresceína sódica de $2 \%$

- rosa bengala a $1,0 \%$.

$\mathrm{O}$ primeiro cora, de verde-claro, as áreas do estroma corneano sem epitélio. A coloração pode ser intensificada com luz azul-cobalto. A segunda cora, 
em roxo, as células epiteliais desvitalizadas da conjuntiva e córnea. A coloração pode ser intensificada com luz verde.

As soluções de fluoresceína são meios de cultura para Pseudomona aeruginosa. Os bastonetes de papel de filtro, impregnados com a fluoresceína seca, minimizam os riscos de contaminação. A rosa bengala é bastante irritante. O paciente, freqüentemente, reclama do teste. Em alguns casos, ocorrem discretas reações alérgico-irritativas.

\section{Corticoesteróides}

São usados, na forma de colírios ou ungüentos oftálmicos, nas conjuntivites alérgicas e no combate às inflamações das estruturas anteriores do olho, incluindo a íris e o corpo ciliar.

Os principais agente de uso tópico são :

- Acetato de prednosolona 1,0\%: Pred-Forte ${ }^{\circledR}$

- Dexametasona álcool 0,1\%: Maxidex ${ }^{\circledR}$

- Fluometolona álcool 0,1\%: Flumex®

Os esteróides de uso tópico potencializam as ceratites por herpes simples e fungos. O paciente sente-se bem, enquanto que a córnea é destruída. Favorece também o aparecimento de catarata. A aplicação local, por mais de 4 semanas, pode causar elevação da pressão intra-ocular, em 30\% das pessoas. Em 5\% dos casos, a elevação é grave com escavação do nervo óptico e perda de parte da visão de campo. Por esses motivos, os corticóides tópicos e suas associações não devem ser prescritos pelo clínico geral.

O uso sistêmico tem indicação no tratamento de inflamações da coróide, retina e vítreo. Nessas condições, são freqüentes o uso de altas doses diárias como, por exemplo, 60 a 80 miligramas diários de prednisolonas. O uso prolongado pode causar catarata, glaucoma, diplopia, paralisia do nervo abducente e papiledema.

\section{Agentes antiinfecciosos}

Existem alguns princípios de uso dos agentes antiinfecciosos tópicos que são:

- devem ser instilados, no mínimo, a cada 3 horas;

- o uso, por mais de dez dias, favorece os fenômenos alergico-irritativos;

- associações com esteróides favorece infecções por fungos;

- preparações de penicilina e estreptomicina são causas comuns de hipersensibilidade, e, por isso, não devem ser usadas topicamente.
Os antibióticos tópicos mais facilmente encontrados em nosso mercado são:

- Cloranfenicol ungüento e colírio.

- Fluoquinolonas ungüento e colírio: Biamotil®, Oflox ${ }^{\circledR}$.

- Aminoglicosídeos ungüento e colírio: Tobrex ${ }^{\circledR}$, Gentamicina ${ }^{\circledR}$.

- Tetraciclina ungüento.

A eficácia da antibioticoterapia, nas infecções intra-oculares, é limitada pela barreira hematoaquosa. Sempre que optar por essa via, devem-se escolher antibióticos que consigam vencer essa barreira com facilidade.

Muitas úlceras de córnea são causadas por fungos normalmente classificados como saprófitas. Os agentes fungicidas tópicos, para o tratamento dessas enfermidades, são pouco efetivos. O uso sistêmico é limitado pela toxicidade e absorção intestinal. Os principais agentes disponíveis são:

- Pimaricina 5\%

- Anfotericina B 2,5 mg/ml

A primeira é mais efetiva nos fungos filamentosos. A segunda, nas leveduras. Ambos são preparados por farmácias de manipulação.

Com exceção do Herpes e os citomegalovirus, as infecções viróticas do olho são refratárias a qualquer tratamento. Felizmente, tendem a curar-se espontaneamente. $\mathrm{O}$ vírus do Herpes simples responde às seguintes medicações tópicas:

- Idoxiuridina colírio e ungüiento: Idu ${ }^{\circledR}$

- Trifluridina ungüento: Zost ${ }^{\circledR}$

- Acyclovir ungüento: Zovirax®

$\mathrm{O}$ acyclovir é o único dos três acima que age também no Herpes zoster. Existe na forma de ungüento oftálmico, de pomada para pele e de comprimidos. As infecções da retina pelo citomegalovírus respondem ao tratamento sistêmico com o gancyclovir.

\section{Agentes hipotensores sistêmicos}

Os agentes hipotensores sistêmicos são usados em Oftalmologia para diminuir drástica e rapidamente a pressão intra-ocular. Servem tanto para o tratamento do glaucoma, como para a diminuição da pressão do corpo vítreo, previamente a uma cirurgia intra-ocular. Esses agentes são separados em dois grandes grupos: (1) agentes hiperosmóticos e (2) inibidores da anidrase carbônica. 
Os agentes hiperosmóticos movem a água do interstício para a circulação sangüínea. São usados, por curto período de tempo, para o abaixamento da pressão intra-ocular, nas situações de emergência como o Glaucoma Agudo. Incluem o manitol endovenoso e o glicerol oral. Usa-se, geralmente, cerca de $250 \mathrm{ml}$ de solução de manitol, correndo de 60 a 80 gotas por minuto. $\mathrm{O}$ glicerol é usado na quantidade de
$1 \mathrm{ml}$ por quilo de peso, dissolvido em suco para ser mais palatável. Obviamente, ele deve ser evitado em pacientes diabéticos.

Os agentes inibidores da anidrase carbônica reduzem a produção do humor aquoso, baixando, assim, a pressão ocular. O mais conhecido é a acetazolamida (Diamox). Os efeitos colaterais mais freqüentes dessa medicação são as parestesias e anorexia.

FARIA e SOUSA SJ de. Clinical therapeutic of ocular problems. Medicina, Ribeirão Preto, 30: 90-93, jan./march 1997.

ABSTRACT: There is a vast therapeutic arsenal for the diagnosis and treatment of the ocular problems. The ways of drug administration include the topical, retrobulbar and systemic. The present work does a summary of the main eye medications of current use separated by their therapeutic groups.

UNITERMS: Therapeutics. Pharmacology. Drugs. Eye.

\section{BIBLIOGRAFIA CONSULTADA}

1 - HAVENER WH. Ocular pharmacology. 5 ed, St Louis, CV Mosby Co, 1983.
2 - BARNHART ER, ed. Physicians' Desk Reference for Ophthalmology. 23th ed, Medical Economics, Oradell, 1995.

Recebido para publicação em 03/01/97

Aprovado para publicação em 30/01/97 